\title{
Appendectomized Patient and Infections after Surgery
}

\author{
Mohammad Reza Asgary* and Hosein Hemmati \\ Department of Surgery, Faculty of Medicine, Guilan University of Sciences, Rasht, \\ Iran; tsasgary85@yahoo.com
}

\begin{abstract}
Appendicitis is one of the common surgeries all over the world, and its diagnosis is difficult and based on clinical examinations or its symptoms. Moreover, after the surgery is accomplished, it is probable that the patient is faced with certain problems and complications. In this regard, the present study was carried out in order to review the infections caused after appendicitis surgery. The databases like PubMed, Google Scholar, and Science Direct and relevant articles were collected, in which keywords like appendicitis surgery, perforation, laparoscopy, and infection had been used. A total number of 6,000 articles were retrieved, out of which, 74 relevant articles were examined. The results of the present study indicated that perforated appendix can be the biggest cause of infection and abscess after intra-abdominal surgery. An increase in the level of C-reactive protein and leukocytes is accompanied with the risk of postoperative complications including infection and abscess. Numerous studies have reported that formation of infection and abscess after laparoscopic appendectomy is a little more than open appendectomy. It is not necessary to consume antibiotics after a non-perforated appendectomy. It is sufficient to consume antibiotics for 3 to 5 days after a perforated appendectomy to prevent infection and abscess. With the above results now it is evident that the appendicitis and its complications are still a common problem among people all over the world. There is still much to discuss among the surgeons with regards to appendicitis and its complications .
\end{abstract}

Keywords: Appendectomy, Infection, Laparoscopic, Perforating

\section{Introduction}

According to the Center for Disease Control and Prevention, an annual number of about 325,000 appendectomy cases happen in the USA ${ }^{1}$. In most of these cases, after patients wake up in the recovery room, they refer to their pain relief ${ }^{2}$. And after they are examined and followed by the surgeon, it is known that they return to their daily lives with a marginal effect on their life quality ${ }^{3}$. All in all, the problems caused after appendectomy occurs in $5-20 \%$ of patients. These problems include bowel obstruction, infection, pneumonia, and death ${ }^{4}$. Extensive studies have been carried out on appendicitis. A simple search on PubMed website using appendicitis as the keyword indicated that about 6000 articles were carried out over 2003-2016, i.e. about 1.17 articles of appendicitis every day. The present review study was carried out in order to examine and identify the predicting and predisposing factors for intra-abdominal infections after appendectomy, whose rate varies between 1 and $10 \%{ }^{5}$. Moreover, different topics that are related to infection after appendectomy, including perforated appendectomy, in comparison to non-perforated appendectomy, including age and obesity, were taken into account.

\section{Perforated and Non-Perforated Appendicitis}

In today's modern world, the rate of perforated appendicitis among people is reported to be $15-20 \%$. In a study carried out on 32,000 appendectomy patients in the database of National Surgical Quality Improvement

*Author for correspondence 
Program (NSQIP), the rate of perforated appendicitis was reported $17 \%^{2}$. Likewise, the results of a study carried out on 9.048 adults in Washington's Surgical Care region indicated that patients who had undergone perforated appendectomy were about $16 \%{ }^{5}$. In children, the most rate of perforation in teenage is similar to adults; however, a significant increase on perforation in ages below 5 years (60\%) and ages below 3 years (86-100\%) was reported ${ }^{6,7}$. Among all postsurgical factors, perforation condition is the biggest risk factor causing infection and abscess after appendicitis surgery. Based on following research result (Table 1), it is clear as to what amount of infection has been resulted in perforated surgery compared to the nonperforated surgery.

Table 1. Postsurgical infection rate in perforated surgery compared to non-perforated surgery

\begin{tabular}{lcc}
\hline Author (year) & $\begin{array}{c}\text { Perforated } \\
\text { appendicitis }\end{array}$ & $\begin{array}{c}\text { Non-perforated } \\
\text { appendicitis }\end{array}$ \\
\hline${ }^{8}$ Kelly et al. (2014) & $8.5 \%$ & $0.8 \%$ \\
${ }^{4}$ Masoomi et al. (2014) & $3.7 \%$ & $1.3 \%$ \\
${ }^{9}$ Romano et al. (2014) & $5.7 \%$ & $0.7 \%$ \\
${ }^{10}$ Markar et al. (2012) & $2.8 \%$ & $0.6 \%$ \\
${ }^{11}$ Asarias et al. (2011) & $5.3 \%$ & $0.88 \%$ \\
\hline
\end{tabular}

According to Table 1, it seems reasonable that the risk rate of infection in non-perforated and perforated appendicitis is about $1[4,8,11]$ and $5 \%[8,9,11]$. respectively. By taking into account the number of appendicitis surgeries carried out every year, it can be concluded as to what percent of patients need treatment of intra-abdominal infection and abscess after appendicitis surgery. As a result, it can be understood what level of tendency exists to identify and solve infection risk factors.

\section{Childhood and Adulthood as Clinical Factors}

It is an important challenge to diagnose what clinical factor can be the predicting and potential factor in internal infection of the organs after appendectomy, and there are numerous contradictory results for this issue in the literature. By reviewing the NSQIP database, Fleming et al. ${ }^{12}$ studied 39,950 appendicitis patients and found various clinical variables related to infection after appendectomy. Those variables included masculinity, date and level of tobacco consumption, systemic inflammatory response syndrome, mean and number of WBC before surgery, emergency method, higher level of injury, and surgery period of longer than 60 minutes, all of which are related with prevalence of infection in internal organs. On the contrary, mean age, BMI, diabetes history, and bleeding disorder history are not correlated with prevalence of infection in internal organs in appendectomy ${ }^{12}$.

A similar study was carried out on 5,097 two-eighteenyear-old children who had undergone appendectomy. It was concluded that there was a correlation between infection of internal organs and complex appendectomy (perforation and abscess infection), high level injuries, putrefaction, and surgery time of over 60 minutes. As opposed to adults; however, it does not seem that an increase in the level of infection in internal organs is related with genders or emergency operations ${ }^{8}$.

\section{Predisposing Factors for Complications after Appendectomy}

The data indicate that the population of appendectomy patients is changing. The number of patients with obesity, multiple diseases, and age of over 65 is increasing. By reviewing the literature, it can be perceived that with over 1.5 million appendectomy patients in the USA from 2003 to 2011 , there has been an increase in various problems and complexities among men, aging over 52 years old, inexperienced hospitals, rural regions, insurance system of individuals over 65, and African American race ${ }^{13}$.

\subsection{Racial Disparities}

In a review study carried out on 39,000 patients in the NSQIP database in 2008, the results showed that the rate of infection after appendectomy was higher among African Americans than whites $(2.7 \%$ vs. $1.7 \%)$. Researchers believe that further investigation should be carried out in order to identify the causes of and interracial grounds for more infection after appendectomy ${ }^{13}$. Whatever the cause is, this issue is important that the disparities should be identified and appropriate individuals need to be trained to become familiar with such complexities and the disparities are gradually eradicated. 


\subsection{Obesity}

Because perforation is the biggest factor predisposing infection of internal organs, it can be predicted that any situation that causes high risk in perforation can result in postsurgical infection. Obesity is a factor that can lead to perforated appendicitis. However, it cannot be concluded that obesity is absolutely the cause of infections in internal organs after appendectomy ${ }^{14,15}$. Although there are disagreements, other researchers have referred to the risk of infection in internal organs among obese children to be $35 \%{ }^{16}$; however, further research should be carried out on this certain population.

\subsection{Young Ages}

As discussed before, children under 5 years are more prone to perforated appendectomy $y^{6,17}$. However, one cannot conclude more infection after appendectomy from the high rate of perforation. Bansal et al. ${ }^{6}$ observed that the rate of infection in organs among children under 5 years is $3.2 \%$. Nevertheless, the rate of perforation among children below 1 year, $1-2$ years, and $2-3$ years is $86 \%, 74 \%$, and $60 \%$ respectively; however, none of those children had an infection after appendectomy. Henry et al. ${ }^{18}$ reported that diarrhea is a predicting factor for development of infection in internal organs after appendectomy ${ }^{6}$. Moreover, Henry et al. concluded that painful period, type and time of consuming antibiotics, the presence of infection at the time of surgery, and surgical techniques are not predictive factors for postsurgical infection and abscess ${ }^{18}$.

\subsection{Old Ages}

On the other end, patients aging over 65 are more predisposed to perforation ${ }^{19}$. This is an important factor for infection risk in internal organs after appendectomy.

\subsection{Prediction Laboratory Data of Infection of Internal Organs}

Published articles have identified different laboratory markers, including WBC, CRP, and bilirubin that are correlated with perforated appendicitis ${ }^{20}$. However, the examined data use this value as a predicting factor for postsurgical infection of internal organs. Thereaux et al. ${ }^{21}$ examined 141 appendectomies in which appendicular peritonitis had been carried out (presence of intraabdominal purulent fluid) and concluded that the number of leukocytes before surgery of more than 17,000 and the
CRP concentration of over $200 \mathrm{mg} / \mathrm{l}$ were correlated with an increase in infection after appendectomy. Age, gender, cycle of symptoms, fever lower than $38^{\circ}$, cystectomy, and presence or absence of fluid leakage are not correlated with infection of internal organs after appendectomy. Other studies indicated that WBC value as the predicting factor for postsurgical infection of internal organs is not convincing ${ }^{8,12,22}$.

\subsection{Delay in Taking the Person to the Operating Room}

As was stated before, it is assumed that any scenario leading to the formation of perforation will result in postsurgical infection. One of the assumptions referred to in the literature is a delay in conducting appendectomy surgery. The results of a review study have recently confirmed that a delay of more than 12 hours can lead to increased perforation and infection of internal organs after appendicitis surgery ${ }^{23}$. Some studies have referred to the opposite of this issue. When the course of antibiotics starts, delay in surgery does not enhance the rate of perforation ${ }^{24,25}$. The results of a meta-analysis carried out in 2014 indicated that a delay of 12-24 hours had no effect on the formation of postsurgical infection ${ }^{26}$.

\section{Laparoscopic Surgical Techniques vs. Open Surgery}

Many scholars have tried to remove appendicitis in a way that no infection occurs after the surgery. After McBurney ${ }^{27}$ proposed his method in appendectomy in 1894, it was employed as a technique to remove appendicitis for a century. In 1981, Semm ${ }^{28}$ implemented laparoscopic method for the first time. With the knowledge of infection after appendectomy, numerous studies have been carried out in order to figure out better methods.

Surgical methods with minimum invasiveness are considered as appropriate techniques for appendectomy. With the knowledge of infection after appendectomy, the literature proposes that compared to open surgery, minimally invasive surgery causes more infection in internal organs after appendicitis surgery. In a metaanalysis, laparoscopic and open surgeries were compared together in 1998. That study indicated that infection of internal organs during laparoscopic surgery and open surgery was respectively 2 and 0.9 percent; however, this 
difference was not significant ${ }^{29}$. Almost a decade later, the results of another meta-analysis focusing on 19952006 indicated that infection of internal organs during laparoscopic surgery was $3 \%$ while $1.6 \%$ in open surgery ${ }^{30}$.

\section{Consuming Antibiotics in Appendectomy}

\subsection{Consuming Antibiotics during Non- Perforated Appendicitis}

In a review, Anderson et al. ${ }^{31}$ examined 45 studies consisting of 9,000 children and adults. They reported that consuming antibiotics caused a decrease in postsurgical infection. Consuming antibiotics is aimed at minimizing postsurgical infection, and researchers have tried to achieve this goal. Regarding non-perforated appendicitis among 700 patients, it was determined that continuous consumption of antibiotics after surgery may be seriously dangerous and increase the level of Clostridium difficile, urinary tract infection, and its survival time ${ }^{32}$. Surgical Infection Society has proposed guidelines against microbes. These guidelines postulate that antibiotics should be consumed before surgery, but not after it. Antibiotic selection should be in a decreasing and instant way. Conventional treatments include twogeneration cephalosporin and long-term spectrum penicillin ${ }^{33}$. Moreover, it has been recommended that antibiotics are not consumed after surgery in adults with non-perforated appendicitis. Daskalakiset al. ${ }^{34}$ carried out a review and concluded that individuals with nonperforated appendicitis need a single and extensive dose of antibiotics before surgery.

\subsection{Consuming Antibiotics during Perforated Appendicitis}

In perforated appendicitis cases, antibiotic consumption duration is discussable. Surgical Infection Society has suggested that children with perforated appendicitis consume an extensive range of antibiotics until clinical symptoms recover (24 hours without fever, normal WBC, and disappearance of symptoms $)^{33}$. According to the recommendations by the Surgical Infection Society, adults should not consume antibiotics more than 7 days unless the patient reaches his natural state. Samples of single-use antibiotics include cefoxitin, ertapenem, and piperacillin-tazobactam ${ }^{35}$.
There have been numerous attempts to identify the duration of antibiotic consumption. Daskalakiset al. ${ }^{34}$ concluded that injecting intravenous antibiotics for at least 3-5 days is recommended until clinical recovery is obtained. Symptoms of clinical recovery includes decrease in fever, CRP, and leukocytosis.

A study carried out in 2014 focused on the difference between consuming antibiotics for 3 and 5 days. The results indicated that there was no significant difference between these two states. All patients were treated with two-generation cephalosporin and metronidazole before and after the surgery ${ }^{35}$.

\section{Diagnosis and Treatment}

There are not many discussions on diagnosing infection of internal organs after appendectomy. In most cases, there is an increase in fever, stomachache, and leukocytosis. When there is clinical doubt, CT scan seems to be a preferable method. If an infection is identified, antibiotics should be prescribed in a large amount and infection should be extracted through penetrating into the skin of that $\operatorname{part}^{36}$.

\section{Discussion and Conclusion}

Infection after appendectomy is an unfavorable complication of appendicitis. After surgery, it occurs in $1 \%$ of severe non-perforated appendicitis ${ }^{9,11}$ while it happens in $5-10 \%$ of perforated surgery ${ }^{2,4,25}$. Perforation certainly causes internal infection after surgery; however, it will be advantageous if other causes are identified. It is reasonable to become aware of this fact that perforation is accompanied by the risk of infection in internal organs after appendicitis surgery, and that factors increasing the risk of perforation are among predicting factors for infection in internal organs of the body after appendectomy. This case is supported by evidence that indicates that failure to treat appendicitis for more than 48 hours can lead to postsurgical complications ${ }^{26}$. Some other factors have been identified to be related to an increase in the rate of perforation including obesity, black race, gender (particularly male), and rural and suburban areas $^{13}$. Relevant data showed that the prevalence of infection after appendectomy is higher among AfricanAmericans than whites $(2.7 \% \text { vs. } 1.7 \%)^{38}$. Moreover, the results reported in the literature indicate that obese 
individuals are more prone to infection of internal organs after appendectomy ${ }^{16}$; however, there are contradictory results in this regard ${ }^{14,15}$. Further studies should be carried out in order to understand such discrepancies better and determine the role of age, gender, and insurance in the rate of infection after an appendectomy. In addition to these variables, researchers should identify laboratory variables that may expose the patients to risk. CRP level of higher than $200 \mathrm{mg} / \mathrm{l}$ and the number of leukocytosis over 17,000 are considered as predictors of infection after appendicitis surgery ${ }^{21}$. When patients who are exposed to risk are identified, this can be used to identify useful approaches to decrease the level of infection after appendicitis surgery. For instance, in non-perforated appendicitis, patients only need to consume antibiotics before surgery and they need not take antibiotics after surgery. It seems that patients with perforated-appendicitis need to use antimicrobial coatings for 3-5 days. In all cases, the patient's clinical condition should be controlled to make sure about improvement in symptoms, decrease in fever, normal state of WBC and CRP ${ }^{34}$.

Numerous studies have focused on whether open surgery or minimally invasive surgery is more effective in decreasing infection after appendectomy. Despite of contradictory results, most meta-analyses have indicated that minimally invasive surgery causes more infection after appendectomy. Despite of this, due to its advantages, laparoscopic surgery is preferred to open surgery by most surgeons. During the recovery period after appendectomy, recurrence or worsening of abdominal pain, fever, and increase in level of WBC and CRP can be a proposed factor for infection. Confirmation with CT scan is the commonest diagnostic method and data that are required for guidance and treatment. In general, appendicitis and its complications are still a problem shared by all people throughout the world. There is still a lot to discuss regarding appendicitis and its complications in the field of surgery.

\section{References}

1. Hall MJ, DeFrances CJ, Williams SN, Golosinskiy A, Schwartzman A. National hospital discharge survey: 2007 summary. Natl Health Stat Report. 2010; 29(29):1-20.

2. Ingraham AM, Cohen ME, Bilimoria KY, Pritts TA, Ko CY, Esposito TJ. Comparison of outcomes after laparoscopic versus open appendectomy for acute appendicitis at 222 ACS NSQIP hospitals. Surgery. 2010; 148(4):625-37.
Available from: file://C:/Users/Wafa/Downloads/Telegram Desktop/video_2016-09-28_01-17-31.mov

3. Kapischke M, Friedrich F, Hedderich J, Schulz T, Caliebe A. Laparoscopic versus open appendectomy-quality of life 7 years after surgery. Langenbeck's Archives of Surgery. 2011; 396(1):69-75.

4. Masoomi H, Nguyen NT, Dolich MO, Mills S, Carmichael JC, Stamos MJ. Laparoscopic appendectomy trends and outcomes in the United States: data from the Nationwide Inpatient Sample (NIS), 2004-2011. The American Surgeon. 2014; 80(10):1074-7.

5. Wilson DG, Bond AK, Ladwa N, Sajid MS, Baig MK, Sains P. Intra-abdominal collections following laparoscopic versus open appendicectomy: an experience of 516 consecutive cases at a district general hospital. Surgical Endoscopy. 2013; 27(7):2351-6.

6. Bansal S, Banever GT, Karrer FM, Partrick DA. Appendicitis in children less than 5 years old: influence of age on presentation and outcome. The American Journal of Surgery. 2012; 204(6):1031-5.

7. Alloo J, Gerstle T, Shilyansky J, Ein SH. Appendicitis in children less than 3 years of age: a 28-year review. Pediatric Surgery International. 2004; 19(12):777-9.

8. Kelly KN, Fleming FJ, Aquina CT, Probst CP, Noyes K, Pegoli W, et al. Disease severity, not operative approach, drives organ space infection after pediatric appendectomy. Annals of Surgery. 2014; 260(3):466-73.

9. Romano A, Parikh P, Byers P, Namias N. Simple acute appendicitis versus non-perforated gangrenous appendicitis: is there a difference in the rate of post-operative infectious complications? Surgical Infections. 2014; 15(5):517-20.

10. Markar SR, Blackburn S, Cobb R, Karthikesalingam A, Evans J, Kinross J, et al. Laparoscopic versus open appendectomy for complicated and uncomplicated appendicitis in children. Journal of Gastrointestinal Surgery. 2012; 16(10):1993-2004.

11. Asarias JR, Schlussel AT, Cafasso DE, Carlson TL, Kasprenski MC, Washington EN, et al. Incidence of postoperative intraabdominal abscesses in open versus laparoscopic appendectomies. Surgical Endoscopy. 2011; 25(8):2678-83.

12. Fleming FJ, Kim MJ, Messing S, Gunzler D, Salloum R, Monson JR. Balancing the risk of postoperative surgical infections: a multivariate analysis of factors associated with laparoscopic appendectomy from the NSQIP database. Annals of Surgery. 2010; 252(6):895-900.

13. Bliss LA, Yang CJ, Kent TS, Ng SC, Critchlow JF, Tseng JF. Appendicitis in the modern era: universal problem and variable treatment. Surgical Endoscopy. 2015; 29(7):1897902.

14. Blanco FC, Sandler AD, Nadler EP. Increased incidence of perforated appendicitis in children with obesity. Clinical Pediatrics. 2012; 51(10):928-32.

15. DeUgarte DA, Stark R, Kaji AH, Yaghoubian A, Tolan A, Lee SL. Obesity does not impact outcomes for appendicitis. The American Surgeon. 2012; 78(2):254-7. 
16. Garey CL, Laituri CA, Little DC, Ostlie DJ, Peter SDS. Outcomes of perforated appendicitis in obese and nonobese children. Journal of Pediatric Surgery. 2011; 46(12):2346-8.

17. Bratton SL, Haberkern CM, Waldhausen JH. Acute appendicitis risks of complications: age and Medicaid insurance. Pediatrics. 2000; 106(1):75-8.

18. Henry MC, Walker A, Silverman BL, Gollin G, Islam S, Sylvester $\mathrm{K}$, et al. Risk factors for the development of abdominal abscess following operation for perforated appendicitis in children: a multicenter case-control study. Archives of Surgery. 2007; 142(3):236-41.

19. Walker A, Hatch Q, Drake T, Nelson DW, Fitzpatrick E, Bingham J, et al. Predictors of appendiceal perforation in an equal access system. Journal of Surgical Research. 2014; 190(1):87-92.

20. Panagiotopoulou I, Parashar D, Lin R, Antonowicz S, Wells A, Bajwa F, et al. The diagnostic value of white cell count, C-reactive protein and bilirubin in acute appendicitis and its complications. The Annals of the Royal College of Surgeons of England. 2013; 95(3):215-21.

21. Thereaux J, Veyrie N, Corigliano N, Servajean S, Czernichow S, Bouillot J-L. Is laparoscopy a safe approach for diffuse appendicular peritonitis? Feasibility and determination of risk factors for post-operative intra-abdominal abscess. Surgical Endoscopy. 2014; 28(6):1908-13.

22. Brenner DJ, Hall EJ. Computed tomography-an increasing source of radiation exposure. N Engl J Med. 2007; 357:2277-84.

23. 23. Papandria D, Goldstein SD, Rhee D, Salazar JH, Arlikar J, Gorgy A, et al. Risk of perforation increases with delay in recognition and surgery for acute appendicitis. Journal of Surgical Research. 2013; 184(2):723-9.

24. Teixeira PG, Sivrikoz E, Inaba K, Talving P, Lam L, Demetriades D. Appendectomy timing: waiting until the next morning increases the risk of surgical site infections. Annals of Surgery. 2012; 256(3):538-43.

25. Drake FT, Mottey NE, Farrokhi ET, Florence MG, Johnson MG, Mock C, et al. Time to appendectomy and risk of perforation in acute appendicitis. JAMA Surgery. 2014; 149(8):837-44.

26. Bhangu A. United Kingdom National Surgical Research Collaborative. Safety of short, in-hospital delays before surgery for acute appendicitis: multicentre cohort study, systematic review, and meta-analysis. Ann Surg. 2014; 259(5):894-903.
27. McBurney C. The incision made in the abdominal wall in cases of appendicitis, with a description of a new method of operating. Annals of Surgery. 1894; 20(1):38.

28. Semm K. Endoscopic appendectomy. Endoscopy. 1983; 15(02):59-64.

29. Golub R, Siddiqui F, Pohl D. Laparoscopic versus open appendectomy: a metaanalysis. Journal of the American College of Surgeons. 1998; 186(5):545-53.

30. Bennett J, Boddy A, Rhodes M. Choice of approach for appendicectomy: a meta-analysis of open versus laparoscopic appendicectomy. Surgical Laparoscopy Endoscopy and Percutaneous Techniques. 2007; 17(4):245-55.

31. Andersen BR, Kallehave FL, Andersen HK. Antibiotics versus placebo for prevention of postoperative infection after appendicectomy. Cochrane Database Syst Rev. 2005; 3.

32. Coakley BA, Sussman ES, Wolfson TS, Bhagavath AS, Choi JJ, Ranasinghe NE, et al. Postoperative antibiotics correlate with worse outcomes after appendectomy for nonperforated appendicitis. Journal of the American College of Surgeons. 2011; 213(6):778-83.

33. Nadler EP, Gaines BA. The Surgical Infection Society guidelines on antimicrobial therapy for children with appendicitis. Surgical Infections. 2008; 9(1):75-83.

34. Daskalakis K, Juhlin C, Påhlman L. The use of pre-or postoperative antibiotics in surgery for appendicitis: a systematic review. Scandinavian Journal of Surgery. 2014; 103(1):14-20.

35. Solomkin JS. Evaluating evidence and grading recommendations: the SIS/IDSA guidelines for the treatment of complicated intra-abdominal infections. Surgical Infections. 2010; 11(3):269-74.

36. van Rossem CC, Schreinemacher MH, Treskes K, et al. Duration of antibiotic treatment after appendicectomy for acute complicated appendicitis. Br J Surg. 2014; 101(6):715-9.

37. Clark JJ, Johnson SM. Laparoscopic drainage of intraabdominal abscess after appendectomy: an alternative to laparotomy in cases not amenable to percutaneous drainage. J Pediatr Surg. 2011; 46(7):1385-9.

38. Scarborough JE, Bennett KM, Pappas TN. Racial disparities in outcomes after appendectomy for acute appendicitis. Am J Surg. 2012; 204(1):11-7. 